\title{
A Body-Weight-Based Method to Estimate Inorganic Arsenic Body Burden Through Tilapia Consumption in Taiwan
}

\author{
B.-C. Chen · C.-M. Liao
}

Received: 26 September 2007 / Accepted: 14 January 2008/Published online: 23 February 2008

(C) Springer Science+Business Media, LLC 2008

\begin{abstract}
In the present study, a stage-classified exposure model is developed to better characterize long-term arsenic (As) accumulation of both genders of children, adolescents, and adults through tilapia consumption in Taiwan. Ingestion rate as well as elimination rate of As are treated dynamically and are used to parameterize the stage-classified accumulation model. Model simulations are carried out to produce temporal changes of As body burden of the residents who consume tilapia from blackfoot disease (BFD)-endemic area in three major cities in Taiwan. The model presented here can be served as a strong framework for refining human health risk assessments through fish consumption.
\end{abstract}

Keywords Arsenic - Tilapia - Body weight .

Human health risk assessment

Arsenic (As) is ubiquitous in the environment from both anthropogenic and natural processes (Liao et al. 2003). Humans may be exposed to As through many sources such as food, water, air and soil; dietary intake is the major exposure route (Yost et al. 2004). It has been recognized that As is a potent human carcinogen of skin, lung and urinary bladder (Vahter 2002). Previous investigation indicated that there is a strong correlation between As

\section{B.-C. Chen $(\bowtie)$}

Department of Post-Modern Agriculture, MingDao University, Changhua 52345, Taiwan, Republic of China

e-mail: bcchen@mdu.edu.tw

C.-M. Liao

Department of Bioenvironmental Systems Engineering, National

Taiwan University, Taipei 10617, Taiwan, Republic of China concentrations in artesian well water and blackfoot disease (BFD) of local inhabitants in southwestern coastal areas of Taiwan (Chen et al. 2001). Today, most of the people living in these areas do not drink water from wells because tap water has been made available in this area. However, groundwater is still used for aquaculture. Farming of tilapia (Oreochromis mossambicus) is the most popular aquacultural species in the BFD area because of its high market value. Our previous study demonstrated that As concentrations in cultured tilapia ranged from $0.94 \pm 0.3$ to $15.1 \pm 8.2 \mu \mathrm{g} \mathrm{g}^{-1}$ dry wt in the BFD area (Liao et al. 2003). This finding indicates the need to assess the potential health risks of humans who consume these contaminated fish (Ling et al. 2005).

Metal cancer risks posed to subpopulations health of children, adolescents and adults through dietary exposure having become a major topic and received increasing attentions in many countries in recent years. Llobet et al. (2003) surveyed the concentrations of arsenic, cadmium, mercury and lead in common foods and evaluated the dietary intake of these metals by children, adolescents, adults, and seniors in Spain. Tsuji et al. (2004) reviewed the regulatory focus on As in the environment and highlighted the need for assessing health risks on a doseper-body-weight basis during childhood. Yost et al. (2004) estimated the dietary intake of inorganic As in the US children and addressed the necessary of accurate dietary intake estimates for risk management decisions. In the absence of a quantitative estimation of dynamic exposure situation, however, it is impossible to accurately delineate the exposure profile for reliable risk assessment.

The purpose of this study was to develop a stage-classified exposure model to better characterize gender-specific long-term As accumulation in children, adolescents, and 
adults through tilapia consumption in Taiwan. Ingestion rate and elimination rate of As were treated dynamically and were used to parameterize the stage-classified accumulation model. Model simulations were carried out to produce temporal changes of As body burden of the residents who consume tilapia from BFD area in three major cities in Taiwan.

\section{Materials and Methods}

To develop the stage-classified exposure model of As accumulation dynamics through fish consumption, we divided the life history of human beings into three developmental phases: children (aged 4-12 years), adolescents (aged 12-18 years), and adults (aged 18-45 years) (Fig. 1). Stage-specific growth rates can be estimated by fitting an exponential growth model to body weight data (Liao et al. 2004)

$\ln W(t)=\ln W_{0, i}+g_{i} t$,

where $t$ denotes the age of an individual in years, $W(t)$ refers to the body weight of an individual at age $t(\mathrm{~kg}), W_{O, i}$ is initial body weight of an individual in stage $i(\mathrm{~kg})$, and $g_{i}$ is the growth rate of an individual in stage $i\left(\right.$ year $\left.^{-1}\right)$. The growth rate for adults $\left(g_{3}\right)$ is setting to zero since no obvious weight change occurred during this stage.

The temporal change of As concentration of an individual through tilapia consumption could be expressed using the first-order one-compartment model based on constant As level in tilapia with time-dependent ingestion rate (Reinfelder et al. 1998),

$\frac{\mathrm{d} C_{b}(t)}{\mathrm{d} t}=\alpha I_{i}(t) C_{f}-\left(k_{e, i}+g_{i}\right) C_{b}(t)$,

where $C_{b}(t)$ is the body burden of inorganic As in an individual $\left(\mu \mathrm{g} \mathrm{kg}^{-1}\right), \alpha$ is the assimilation efficiency of the individual, $C_{f}$ is the inorganic As concentration in tilapia ( $\mu \mathrm{g} \mathrm{g}^{-1}$ wet $\mathrm{wt}$ ), and $k_{e, i}$ is the individual elimination rate of As in stage $i\left(\right.$ year $\left.^{-1}\right)$. The ingestion rate of tilapia in stage $i, I_{i}(t)\left(\mathrm{g} \mathrm{kg}^{-1}\right.$ year $\left.{ }^{-1}\right)$, can be expressed as

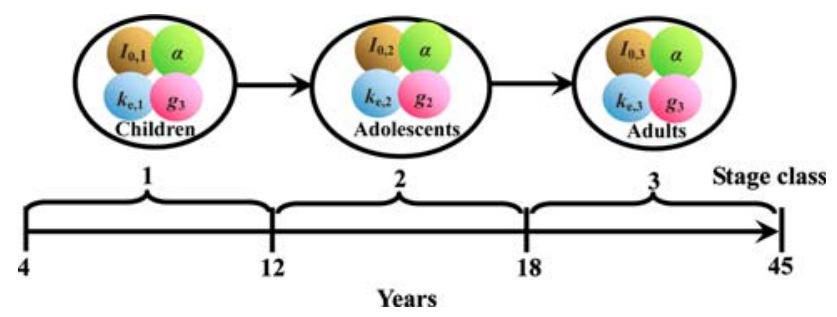

Fig. 1 A conceptual diagram used to derive the stage-specific exposure model of As accumulation dynamics through tilapia consumption. The meanings of the symbols are given in the text
$I_{i}(t)=\frac{C R}{W(t)}$,

where $C R$ is the annual consumption rate of tilapia $\left(\mathrm{g} \mathrm{year}^{-1}\right.$ ). By introducing an initial ingestion rate of tilapia of stage, $I, I_{0, i}=\frac{C R}{W_{0, i}}=$ const, the solution to Eq. 2 is given by (Gross-Sorokin et al. 2003)

$C_{b}(t)=\left(\frac{\alpha I_{0, i} C_{f}}{k_{e, i}}\right) \cdot\left[e^{-g_{i} t}-e^{-\left(k_{e, i}+g_{i}\right) t}\right]$.

Therefore, the stage-specific body burden of As for children, adolescents, and adults through tilapia consumption can be expressed as

(1) For children $\left[T_{1}<t<T_{2}, \quad\left(T_{1}=4\right.\right.$ year, and $T_{2}=12$ year $\left.)\right]$

$C_{b}(t)=\left(\frac{\alpha I_{0,1} C_{f}}{k 1}\right) \cdot\left[e^{-g_{1}\left(t-T_{1}\right)}-e^{-\left(k_{e, 1}+g_{1}\right)\left(t-T_{1}\right)}\right]$,

(2) For adolescents $\left[T_{2}<t<T_{3}, \quad\left(T_{2}=12\right.\right.$ year, and $T_{2}=18$ year $\left.)\right]$

$C_{b}(t)=\left(\frac{\alpha I_{0,2} C_{f}}{k_{e, 2}}\right) \cdot\left[e^{-g_{2}\left(t-T_{2}\right)}-e^{-\left(k_{e, 2}+g_{2}\right)\left(t-T_{2}\right)}\right]$ $+C_{b}\left(T_{2}\right) \cdot e^{-\left(k_{e, 2}+g_{2}\right)\left(t-T_{2}\right)}$,

(3) For adults $\left[T_{3}<t<T_{4}, \quad\left(T_{3}=18\right.\right.$ year, and $T_{4}=45$ year $\left.)\right]$

$C_{b}(t)=\left(\frac{\alpha I_{0,3} C_{f}}{k_{e, 3}}\right) \cdot\left[1-e^{-k_{e, 3}\left(t-T_{3}\right)}\right]+C_{b}\left(T_{3}\right)$ $\cdot e^{-k_{e, 3}\left(t-T_{3}\right)}$.

Five parameters, stage-specific growth rates $\left(g_{i}\right)$, assimilation efficiency $(\alpha)$, initial ingestion rate of tilapia in stage $i\left(I_{O, i}\right)$, individual elimination rate of As in stage $i$ $\left(k_{e, i}\right)$, and the inorganic As concentration in tilapia $\left(C_{f}\right)$, in Eqs. 5-7 are needed to predict the long-term body burden of As through tilapia consumption for different subpopulation.

Stage-specific growth rates for children and adolescents were calculated by fitting Eq. 1 to body weight data released from the Department of Health, Taiwan (http:// www.doh.gov.tw) (Table 1). The stage-specific growth rates are 0.11 year $^{-1}$ for male and 0.13 year $^{-1}$ for female during childhood. On the other hand, the stage-specific growth rates for male and female of adolescents are estimated to be 0.06 and 0.02 year $^{-1}$, respectively.

Pomroy et al. (1980) and Caussy (2003) suggested that human GI tract absorbs $80-90 \%$ of As. Caussy (2003) further indicated that there are no data to support that absorption of As from the gut in children differs from that in adults. Consequently, a value of 0.85 of assimilation efficiency is applied for all life stages of humans in the present study. 
Table 1 Optimal fits of growth rate model for body weight data of children (aged 4-12 years) and adolescents (aged 13-18 years)

\begin{tabular}{llll}
\hline Stage & Fitting equation & $\begin{array}{l}\text { Growth rate, } \\
g\left(\text { year }^{-1}\right)\end{array}$ & $r^{2}$ \\
\hline $\begin{array}{l}\text { Children } \\
\quad \text { Male }\end{array}$ & $\ln W(t)=0.11 t+2.43$ & 0.11 & 0.994 \\
$\quad$ Female & $\ln W(t)=0.13 t+2.25$ & 0.13 & 0.997 \\
$\begin{array}{c}\text { Adolescents } \\
\quad \text { Male }\end{array}$ & $\ln W(t)=0.06 t+3.15$ & 0.06 & \\
$\quad$ Female & $\ln W(t)=0.02 t+3.68$ & 0.02 & 0.825 \\
& & & 0.770 \\
\hline
\end{tabular}

Data on annual consumption rates of tilapia can be obtained by dividing the annual consumption quantities of tilapia in three major cities, Taipei, Taichung, and Kaohsiung, provided by Fisheries Administration of Taiwan by the number of residents in each assigned cities (Ling et al. 2005). The initial ingestion rate of tilapia for different stages and genders can then be calculated by dividing tilapia consumption rates by initial body weight of different life stages.

Mann et al. (1996) developed a physiologically based pharmacokinetic model for As exposure and demonstrated that feces excretion rate of As of humans can be scaled to body weight by the following equation

$k_{e l}=\left(56.60 \times B W^{0.328}+237\right) \times 0.0492 \times B W^{0.661}$.

Vahter (2002) reported that the mean As elimination for adults was estimated to be 0.66 year $^{-1}$. Assuming that the individual elimination rate is proportion to its excretion rate of As, the elimination rate of different life stage can thus be obtained.

The total As concentration in the muscle tissue of tilapia from the BFD area was reported to be $3.55 \pm 0.42 \mu \mathrm{g} \mathrm{g}^{-1}$ on a dry-weight basis (Liao et al. 2003). A water content of $80 \%$ adapted from Lung et al. (2003) is used to convert this value into a wet-weight basis. Since the estimation of human health risks from the intake of seafood products was suggested to depend on the intake of inorganic As in these products (Muñoz et al. 2000), the total As concentration was then multiplied by the inorganic As percentage of tilapia (7.4\%) reported by Huang et al. (2003). Consequently, the average inorganic As concentration in tilapia used throughout this study was estimated to be $1.31 \mu \mathrm{g} \mathrm{g}^{-1}$ wet wt.

All parameters used to calculate the As body burden of an individual through tilapia consumption are introduced into Eqs. 5-7. Model simulations were carried out to produce long-term arsenic body burden through tilapia consumption of both genders living in Taipei, Taichung, and Kaohsiung in Taiwan.

\section{Results and Discussion}

The simulation results are presented in Fig. 2. The inorganic As body burden of residents living in Taipei, Taichung, and Kaohsing all reached their maximum levels for children aged 8 years, with the values of 42.26, 110.45, and $12.65 \mathrm{\mu g} \mathrm{kg}^{-1}$ for male, and 39.13, 102.24, and $11.71 \mu \mathrm{g} \mathrm{kg}^{-1}$ for female, respectively. The accumulated As levels then approached stability for adults after 20-year As exposure via consumption of contaminated tilapia. The stable concentrations of residents living in Taipei, Taichung, and Kaohsing are, respectively, 13.79, 36.02, and $4.13 \mu \mathrm{g} \mathrm{kg}^{-1}$ for male, and $15.89,41.52$, and $4.75 \mu \mathrm{g} \mathrm{kg}^{-1}$ for female.

In view of Eq. 4, a higher annual consumption rate of tilapia explicitly resulted in a higher As body burden. Compared to residents in the other two cities, the inorganic As body burden was the highest for residents in Taichung, which had the highest annual consumption rate of tilapia. This result is in a good agreement with the finding of a previous study regarding human health risk assessment in Taiwan (Ling et al. 2005). In the case of male and female, inorganic As concentrations in male were higher than those in female in the 6-16-year group, whereas in the 16-45year group show opposite. These differences between the two groups mainly resulted from the differences in body weight, which was critical parameter of the model derived in this study.

It was generally recognized that older age groups would reflect more cumulative exposure than children because of increasing exposure duration. The predicted results in the present study, however, showed that children had higher accumulated As levels than that in older age groups on a per-unit-body-weight basis (Fig. 2). This was evident that not only uptake rate but also elimination rate of inorganic As were considered in the model for estimating accumulated As levels. According to Eq. 8, the smaller body weight of children resulted in the slow elimination rates, thus increased As accumulation rates of children relative to the older age groups. Compared with data from the literature (Tsuji et al. 2004), our results were agreed well with a clinical investigation of age-specific As dose from longterm exposure of As for a population in Chile. More data, however, are necessary to refine the model.

Recently, there is no legislation to regulate As concentration in fish in Taiwan (Lin et al. 2005). In the international level, the maximum permitted levels of inorganic As level in seafood is $1 \mathrm{gg} \mathrm{g}^{-1}$ wet wt in Australian and $6 \mu \mathrm{g} \mathrm{g}^{-1}$ wet wt in New Zealand (Muñoz et al. 2000). In the present study, it was assumed that exposure to inorganic As of residents in three major cities in Taiwan occurred only from consumption of tilapia farmed in the As-contaminated area (i.e., BFD area). A relatively higher 
Fig. 2 Simulation results of long-term inorganic arsenic body burden through tilapia consumption of residents living in three major cities in Taiwan

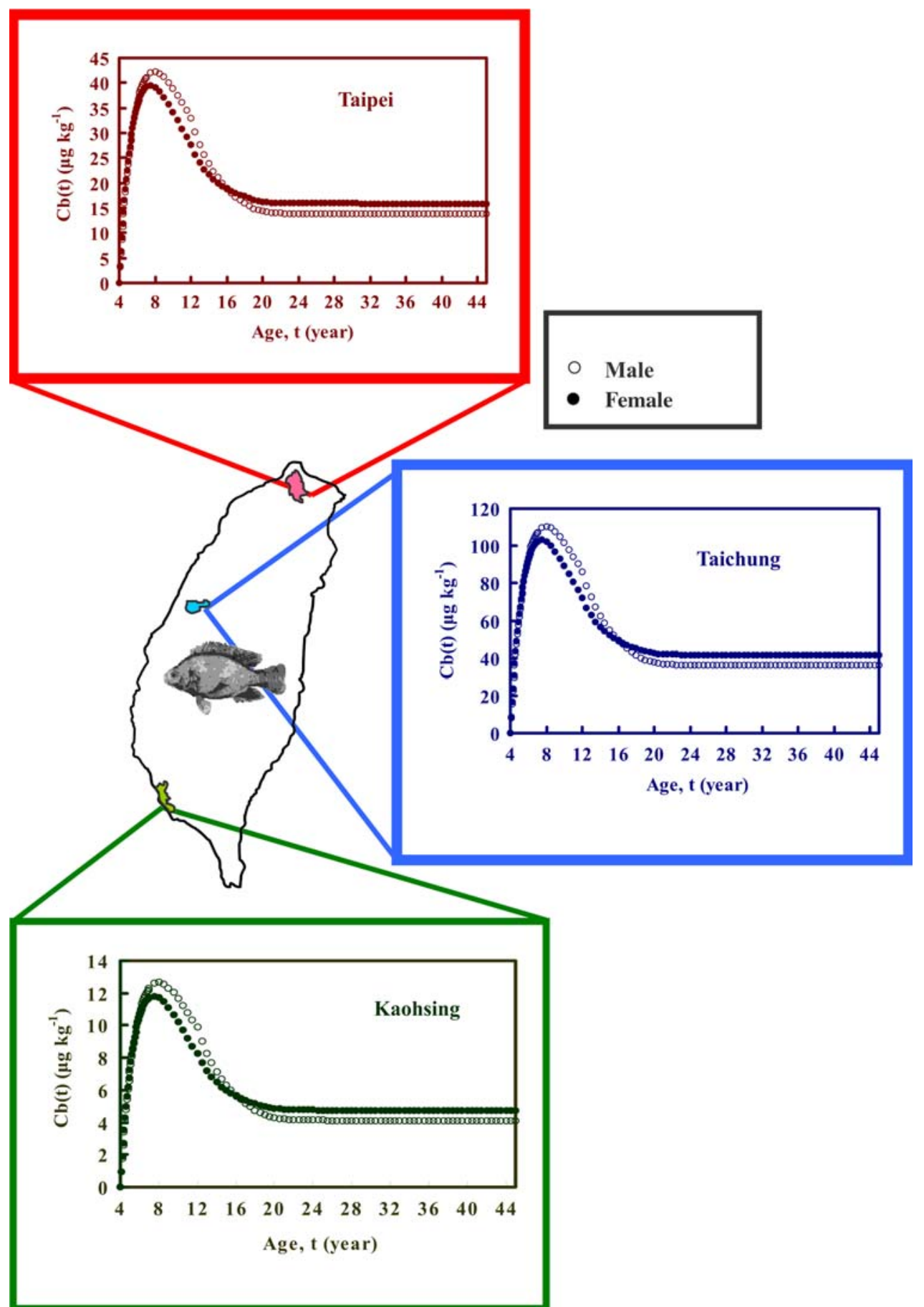

inorganic As level in tilapia (1.31 $\mathrm{gg} \mathrm{g}^{-1}$ wet wt) was thus adopted to estimate long-term As accumulation in city residents. In fact, although not all tilapia consumed was from the BFD area, more than 50\% of farmed tilapia was produced in this area of Taiwan (Huang et al. 2003). Consequently, the As accumulation estimated here could be served as a conservative evaluation while assessing human health risks via tilapia consumption.

The intake estimates of inorganic As in this study are subject to restriction from tilapia consumption. In reality, however, people may be exposed to As via a wide variety of foods such as rice, flour, and beef (Schoof et al. 1999). Inasmuch as the present method was developed by physical perspective instead of any biological and/or chemical characteristics, it could equally be applied to characterize As accumulation from other foods. Therefore, accurate estimates of inorganic As intakes could be achieved by combining food consumption data from all dietary sources.

In conclusion, we developed a body-weight-based method in this study to estimate long-term inorganic As 
body burden via tilapia consumption by city residents in Taiwan. Both ingestion and elimination parameters involved in this model were predominantly dependent on the body weight of the population concerned. The proposed model provides a pivotal effort for assessing human health risks via lifetime exposure to arsenic in the population of different age and gender. However, further laboratory studies of important input parameters are necessary to refine the model. The model presented here could serve as a strong framework for refining human health risk assessments through fish consumption.

Acknowledgments This study was supported by the National Science Council of Republic of China under Grant NSC 95-2313-B-451001.

\section{References}

Caussy D (2003) Case studies of the impact of understanding bioavailability: arsenic. Ecotoxicol Environ Saf 56:164-173

Chen CJ, Hsueh YM, Tseng MP, Lin YC, Hsu LI, Chou WL, Chiou HY, Wang IH, Chou YL, Tseng CH, Liou SH (2001) Individual susceptibility to arseniasis. In: Chappell WR, Abernathy CO, Calderon RL (eds) Arsenic exposure and health effects IV. Elsevier, Oxford, UK, pp 135-143

Gross-Sorokin MY, Grist EPM, Cooke M, Crane M (2003) Uptake and depuration of 4-nonylphenol by the benthic invertebrate Gammarus pulex: how important is feeding rate? Environ Sci Technol 37:2236-2241

Huang YK, Lin KH, Chen HW, Chang CC, Liu CW, Yang MH, Hsueh YM (2003) Arsenic species contents at aquaculture farm and in farmed mouthbreeder (Oreochromis mossambicus) in blackfoot disease hyperendemic areas. Food Chem Toxicol 41:1491-1500

Liao CM, Chen BC, Singh S, Lin MC, Liu CW, Han BC (2003) Acute toxicity and bioaccumulation of arsenic in tilapia (Oreochromis mossambicus) from a blackfoot disease area in Taiwan. Environ Toxicol 18:252-259

Liao CM, Chen BC, Tsai JW, Chen JW, Ling MP, Chou YH (2004) A parsimonious AUC-based biokinetic method to estimate relative bioavailable zinc to abalone Haliotis diversicolor supertexta. Aquaculture 232:425-440

Lin MC, Lin HY, Cheng HH, Chen YC, Liao CM, Shao KT (2005) Risk assessment of arsenic exposure from consumption of cultured milkfish, Chanos chanos (Forsskal), from the arseniccontaminated area in southwestern Taiwan. Bull Environ Contam Toxicol 75:637-644

Ling MP, Liao CM, Tsai JW, Chen BC (2005) A PBTK/TD Modeling-based approach can assess arsenic bioaccumulation in farmed tilapia (Oreochromis mossambicus) and human health risks. Integr Environ Assess Manag 1:40-54

Llobet JM, Falco G, Casas C, Teixido A, Domingo JL (2003) Concentrations of arsenic, cadmium, mercury, and lead in common foods and estimated daily intake by children, adolescents, adults, and seniors of Catalonia, Spain. J Agric Food Chem 51:838-842

Lung SCC, Chen CF, Hu SC, Bau YP (2003) Exposure of Taiwan residents to polychlorinated biphenyl congeners from farmed, ocean-caught, and imported fish. Environ Sci Technol 37:4579_ 4585

Mann S, Droz PO, Vahter M (1996) A physiologically based pharmacokinetic model for arsenic exposure. II. Validation and application in humans. Toxicol Appl Pharmacol 140:471-486

Muñoz O, Devesa V, Suñer MA, Vélez D, Montoro R, Urieta I, Macho ML, Jalón M (2000) Total and inorganic arsenic in fresh and processed fish products. J Agric Food Chem 48:4369-4376

Pomroy C, Charbonneau SM, McCullough RS, Tam GKH (1980) Human retention studies with arsenic. Toxicol Appl Pharmacol 53:550-556

Reinfelder JR, Fisher NS, Luoma SN, Nichols JW, Wang WX (1998) Trace element trophic transfer in aquatic organisms: a critique of the kinetic model approach. Sci Total Environ 219:117-135

Schoof RA, Yost LJ, Eickhoff J, Crecelius EA, Cragin DW, Meacher DM, Menzel DB (1999) A market basket survey of inorganic arsenic in food. Food Chem Toxicol 37:839-846

Tsuji JS, Benson R, Schoof RA, Hook GC (2004) Health effect levels for risk assessment of childhood exposure to arsenic. Regul Toxicol Pharmacol 39:99-110

Vahter M (2002) Mechanisms of arsenic biotransformation. Toxicol 181-182:211-217

Yost LJ, Tao SH, Egan SK, Barraj LM, Smith KM, Tsuji JS, Lowney YW, Schoof RA, Rachman NJ (2004) Estimation of dietary intake of inorganic arsenic in U.S. children. Hum Ecol Risk Assess 10:473-483 